\title{
Crying significantly reduces absorption of aerosolised drug in infants
}

\author{
R Iles, P Lister, A T Edmunds
}

\begin{abstract}
Aim-Therapeutic aerosols are routinely used in the management of infant obstructive airways disease. Infants often become distressed during administration. The aim of this study was to determine the influence of distress and disease severity on the absorption of aerosolised drug in this age group.

Methods-Fifteen infants, eight with resolving chronic lung disease of prematurity (mean age, 13 months), and seven infants with normal birth histories (mean age, 11 months) were studied. Flow through small airways was assessed by measurement of partial forced expiratory flow volume curves. Each infant was then given a dose of $20 \mathrm{mg}$ nebulised sodium cromoglicate via a Sidestream nebuliser and distress was graded as: 1, not distressed; 2, distressed. Infants were excluded if contact with the mask was lost for more than 10 seconds. Urine was collected for eight hours and analysed for excreted drug by radioimmunoassay.

Results-Sodium cromoglicate is absorbed by the respiratory epithelium, and undergoes renal $(43 \%)$ and hepatic $(57 \%)$ excretion. A mean of $0.43 \%$ of the total nebulised drug dose was excreted in the urine of the non-distressed infants compared with $0.11 \%$ of total dose in the distressed infants. Flow through the small airways was significantly reduced in infants with chronic lung disease of prematurity. Maximum flow at functional residual capacity did not correlate with the amount of drug in the urine, but the degree of distress did.
\end{abstract}

Conclusion-To maximise absorption, nebulised drugs should be given to settled infants. The degree of airways disease does not influence drug absorption in this age group.

(Arch Dis Child 1999;81:163-165)

Keywords: chronic lung disease of prematurity; drug administation; aerosols; absorption; distress

Studies have shown that under optimum conditions $14-40.7 \%$ of inhaled drug is potentially delivered from a variety of devices to the lungs of cooperative adults and children. ${ }^{12}$ There are few studies measuring deposition of aerosol particles in uncooperative children. Numerous therapeutic trials of inhaled drugs for the treatment of asthma or infant wheeze have failed to show appreciable benefit. Total drug deposition is thought to be age related, being greater in older children. ${ }^{34}$ Alderson and colleagues $^{5}$ showed that drug deposition was patchy, concentrated around the central airways, and varied with the severity of disease. These data were confirmed by Hiller et al. ${ }^{6}$ The rationale for using adult doses in paediatric patients became obvious when it was demonstrated by Salmon and colleagues ${ }^{7}$ that less than $1 \%$ of drug administered by nebuliser or metered dose inhaler is deposited in the lungs of 9 to 30 month old infants. There are few clinical data regarding aerosol treatment in the younger age group, which is more complex, with or without obstructive airways disease..$^{8-11}$

We speculated that the crying infant, inhaling with a larger tidal volume, would absorb more drug but found the reverse to be true.

\section{Methods}

We recruited 18 infants aged between 9 and 13 months. They were sedated with $100-150 \mathrm{mg} /$ $\mathrm{kg}$ of triclofos sodium one hour before the application of a "squeeze" to their chest wall to produce a partial forced expiratory flow volume curve (PEFC), as described by Clark and Silverman. ${ }^{12}$ We used jacket inflation pressures of $10 \mathrm{cmH}_{2} \mathrm{O}$ to $70 \mathrm{cmH}_{2} \mathrm{O}$ (rising at increments of $5 \mathrm{cmH}_{2} \mathrm{O}$ ). Five inflations were performed at each pressure. The RASP software package (Physiologic Ltd, Cambridge, UK) was used to collect and analyse the data. The equipment was calibrated before and after each patient session.

Infants were monitored using a transcutaneous $\mathrm{pO}_{2}$ monitor and pulse oximeter. Monitoring started after receiving sedation and was continued throughout the procedure until the child was fully awake.

Specific criteria suggested by Clark and Silverman ${ }^{12}$ were identified, namely, time to peak jacket inflation, jacket inflation lead time, stable end expiratory level, and expiratory reserve volume. Data that did not meet these specific criteria were excluded. The maximum value for maximum flow at functional residual capacity (V'maxFrc) was taken as the reference data.

Nebulised sodium cromoglicate $(20 \mathrm{mg}$ ) was administered by a Sidestream disposable nebuliser (Medic-Aid, West Sussex, UK), between two and six hours after sedation for PEFC. Most $(80 \%)$ of the aerosol particles produced by the Sidestream are less than $5 \mu \mathrm{m}$ when driven by a gas flow rate of $6 \mathrm{l} / \mathrm{min}$. The drug was made up to $4 \mathrm{ml}$ with normal saline and was nebulised for 10 minutes. A Hudson oxygen face mask (Henleys Medical Supplies, UK) was attached to the nebuliser and held against the face of the infant throughout the procedure. 
Table 1 Mean maximal flow at functional residual capacity (V'maxFrc) and percentage of total sodium cromoglicate excreted in the urine (\% total SC) for infants with normal birth histories and those with chronic lung disease of prematurity

\begin{tabular}{lcl}
\hline Group & V'maxFrc $(\mathrm{ml} / \mathrm{s})$ & \% Total SC \\
\hline Normal & 150 & \\
& 94.7 & 0.6 \\
& 205 & 0.3 \\
& 85 & 0.47 \\
& 82.5 & 0.37 \\
& 250 & 0.05 \\
Mean & 173 & 0.08 \\
SE & 148.60 & 0.13 \\
Chronic lung disease of prematurity & 0.28 \\
& 50 & 0.07 \\
& 56.4 & 0.03 \\
& 10.2 & 0.28 \\
& 32 & 0.07 \\
& 25 & 0.16 \\
& 57 & 0.6 \\
Mean & 80 & 0.27 \\
SE & 8.8 & 0.2 \\
& 39.92 & 0.65 \\
& 8.8 & 0.28 \\
& & 0.08
\end{tabular}

A significant difference was found between V'max Frc in the normal and chronic lung disease groups $(p<0.001)$. No significant difference was found for $\%$ total SC $(p=0.977)$.

Infant distress was graded as: 1 , no or minimal distress, normal tidal breathing pattern, normal respiratory rate; and 2 , distressed and/or crying with raised respiratory rate. If the infant was so distressed that the mask lost contact with the child's face for more than $10 \mathrm{sec}-$ onds, nebulisation was discontinued and the child was excluded from the study.

Urine was subsequently collected for eight hours into perineal urine bags that had been modified to drain continuously into 24 hour collection bags. Leakage was measured by recording the change in weight of a pre-weighed nappy (diaper) placed on the infant at the start of the study. Data were excluded from statistical analysis if there was a $>20 \%$ leakage of urine. Urine samples were frozen immediately. Batch analysis was carried out on coded samples by radioimmunoassay. Results were expressed as the total sodium cromoglicate $(\mu \mathrm{g})$ collected over eight hours. Because $43 \%$ of sodium cromoglicate is renally excreted, the total amount measured in urine was divided by a correction factor of 0.43 and was then expressed as a percentage of the administered dose. Standard quality control samples of plasma and urine were measured. Differences between groups were compared by the Mann-Whitney test.

\section{Results}

We recruited 18 infants but excluded one when she became too distressed during nebulisation and two after a $>20 \%$ leak of urine. Statistical analysis was performed on 15 infants. Of the eight infants who were not distressed, four had resolving chronic lung disease of prematurity (CLD). Seven infants formed the distressed group, of whom four had CLD. The mean V'maxFrc for the infants with normal birth histories was $148.6 \mathrm{ml} / \mathrm{s}$ (SE, 24.5), for the infants with CLD it was $39.93 \mathrm{ml} / \mathrm{s}$ (SE, 8.8; $\mathrm{p}<0.001$ ) (table 1). In the settled infants, the mean percentage of total drug excreted in the urine was $0.43 \%$ (SE, $0.06 \%$; range, $0.2-$

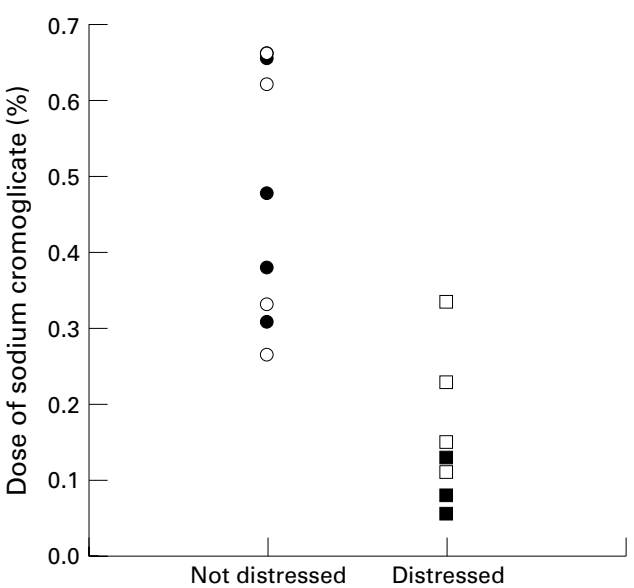

Figure 1 Individual data plot of estimated absorption of a nebulised dose of sodium cromoglicate plotted against the degree of infant distress. Normal infants are shown in white, infants with chronic lung disease of prematurity in black. Distressed infants absorbed significantly less drug than settled infants $(p<0.001)$.

$0.65 \%)$. In distressed infants this was $0.11 \%$ (SE, $0.03 \%$; range, $0.01-0.28 \%$ ) of the total dose. The degree of distress was inversely associated with the percentage of total dose excreted in the urine $(\mathrm{p}<0.001)$ (fig 1$)$. Those infants who were more settled absorbed more of the drug. We recruited too few patients to perform statistical analysis within the distressed group. Visual inspection of the plotted data suggest that the combination of severe airways disease in a distressed child might result in an even smaller percentage dose of drug being absorbed. Statistically, within the whole study group, the severity of lung disease was not associated with the amount of drug found in the urine, even when matched for degree of distress.

\section{Discussion}

Our results show that the administration of a nebulised drug to an unsettled or crying infant significantly reduces the small fraction of that drug that is known to be absorbed by the lungs. This disproves the commonly held belief that a crying child inhales a greater proportion of administered drug. Therefore, every effort should be made to administer aersolised drugs to quiet or sleeping infants.

Using methods similar to Salmon et $a l l^{7}$ we achieved similar low urinary concentrations of sodium cromoglicate, reinforcing the evidence that delivery by aerosol is poor in this age group. These data agree with studies concerned primarily with the measurement of bronchial hyperreactivity in infants and preschool children, ${ }^{13}$ which showed drug deposition efficiency increased markedly when the same aerosolised drug was given to a sleeping infant.

We found no association between the severity of airways disease and the amount of drug in the urine within the two groups. In the infant, nasal filtration of aerosol particles could be a crucial factor in this reduction. Calculations based on the Weibel model of adult airways ${ }^{3}$ suggest that impaction is the dominant mechanism in the more proximal small airways and sedimentation is dominant in the more distal 
airways. If the same applies to infants under the conditions studied, a change in small airways calibre might not alter total small airways deposition. The statistical detection of either mechanism could not be achieved by this study.

The pharmokinetics of sodium cromoglicate after inhaled, intravenous, and oral administration have been described in adults. ${ }^{14}$ It is absorbed efficiently by the respiratory tract but not the gastrointestinal or nasal epithelium. It rapidly enters the plasma and is excreted by the kidneys (43\%) and biliary tree (57\%). Radioimmunoassay of the unchanged drug can be performed. ${ }^{15}$ There are no data concerning pharmokinetics in young children. We assumed, like others, ${ }^{7}$ that they did not differ from adult data.

Data from studies performed on adults suggest that the efficiency with which drug is deposited in the lung by most jet nebulisers is $1-5 \%$, whereas the efficiency of metered dose inhalers is $10-14 \%$. Under optimum conditions, the mean deposition on in line filters for a detergent coated spacer device has been recorded to be as high as $40 \%$ for children of a similar age range. $^{2}$ Each delivery system has specific advantages, ${ }^{9}{ }^{16}$ but recent evidence supports the use of metered dose inhalers and spacers rather than nebulisation for delivery of $\beta_{2}$ agonists, at least. ${ }^{17}$ We chose to use the Sidestream nebuliser because it is a commonly used device and, at the time of our study, it had the highest percentage of aerosol output volume in the respirable range $(<5 \mu \mathrm{m})$ compared with other commercially available nebulisers. Our results suggest that the "compliance" of the infant is of greater practical importance than device type.

We conclude from our data and from reviewing published work that only a small proportion of nebulised drug is absorbed by infants and that this proportion is significantly reduced if the child is distressed during drug delivery.
The authors thank Dr D Wilkinson of Fisons Research and Development, and Dr J Bennet of Hazelton Europe Ltd for their help with the measurement of sodium cromoglicate.

1 Newman SP, Pavia D, Garland N, Clark SW. Effects of various inhalation modes on the deposition of radioactive pressurised aerosols. Eur f Respir Dis 1982;63:57-65.

2 Wildhaber JH, Devadason SG, Hayden MJ, Eber E, Summers QA, LeSouef PN. Aerosol delivery to wheezy infants: a comparison between a nebuliser and small volume spacers. Pediatr Pulmonol 1997;23:212-16.

3 Hofmann W, Martonen TB, Graham RC. Predicted deposition of nonhygroscopic aerosols in the human lung as a function of subject age. Fournal of Aerosol Medicine 1989;2: $49-68$.

4 Chua HL, Collis GG, Newbury AM, et al. The influence of age on aerosol deposition in children with cystic fibrosis. Eur Respir f 1994;7:2185-91.

5 Alderson PO, Secker-Walker RH, Strominger DB. Pulmonary deposition of aerosols in children with cystic fibrosis. F Pediatr 1974;84:479-84.

6 Hiller C, Warren R, Wilson D. Quantitative deposition of multi modal aerosols in the respiratory tract of patients with cystic fibrosis and children with normal lungs. $C F$ Club Abstracts, Washington, DC 1982:121.

7 Salmon B, Wilson NM, Silverman M. How much aerosol reaches the lungs of wheezy infants and toddlers? Arch Dis Child 1990;65:401-4.

8 Chang HK, Menon AS. Airflow dynamics in the human airways. In: Moran F, Newhouse MT, Dolovich MB, eds. Aerosols in medicine: principles, diagnosis and therapy. Aerosols in medicine: principles, diag

9 Freelander M, Van Asperen PP. Nebuhaler versus nebuliser in children with acute asthma. BMF 1984;288:1873-4.

10 Knight V, Yu CP, Gilbert BE, Orr R. Ribavirin aerosol dosage according to age of patient and other variables. F Infect Dis 1988;158:443-8.

11 LeSouf PN, Collis GG, Cole CH. Dilution of aerosols by air entrainment in children. Part 2 [abstract]. Am Rev Respir Dis 1990;141:A900.

12 Clark JS, Silverman M. Partial expiratory flow volume loops. In: Dezateaux CA, Fletcher M, Rabbette PS, Stanger LJ, Stocks J, eds. A manual of infant lung function testing. London: Institute of Child Health, 1991:83-92.

13 Murakami G, Igarashi T, Adachi Y. Measurement of bronchial hyperreactivity in infants and preschool children using a new method. Ann Allergy 1990;64:383-7.

14 Neale MG, Brown K, Hodder RW, Auty RM. The pharmokinetics of sodium cromoglycate in man after intravenous and inhalation administration. $\mathrm{Br} \mathcal{F}$ Clin Pharmacol 1986;22:373-82.

15 Brown K, Gardner JJ, Lockley WJS, Preston JR, Wilkinson DJ. Radioimmumoassay of sodium cromoglycate in human plasma. Ann Clin Biochem 1983;20:31-6.

16 Everard ML, Clark AR, Milner AD. Drug delivery from jet nebulisers. Arch Dis Child 1992;67:586-91.

17 Cates CJ. Holding chambers versus nebulisers for $\beta_{2}$ agonist treatment of acute asthma [Cochrane review]. In: The Cochrane Library, Issue 1. Oxford: 1999. 